\title{
Notas sobre me encontrar
}

Usei uma blusa vermelho bordô, um all star vermelho, maquiei-me e passei um batom vermelho nos lábios. Guardei minhas coisas numa bolsa vermelha. Antes de ir para meu estágio passei no Taguacenter (onde compro materiais para artesanato) e o que presenciei foi um momento estranho, ímpar pra mim.

Modo de fazer:

Como atrair atenção, olhares e julgamentos.

\section{1- Seja mulher}

2- Vista-se de vermelho

3- Use acessórios vermelhos

4- Erga a cabeça e siga com passos firmes pelo seu caminho

5- Se tiver tatuagem, hoje parece que estão mais visíveis. Mostre todas possíveis!

6- Use seu patuá, parece que isso também atrai olhares

7- Tenha em seu ser, hormônios à flor da pele. Eles também se apresentam externamente .

8- Solte a cabeleira cacheada mesclada ao suave perfume que usa cotidianamente e caminhe. Apenas, caminhe.

Acredite, todos seres conservadores e escrotos vão te olhar como quem te condena! 


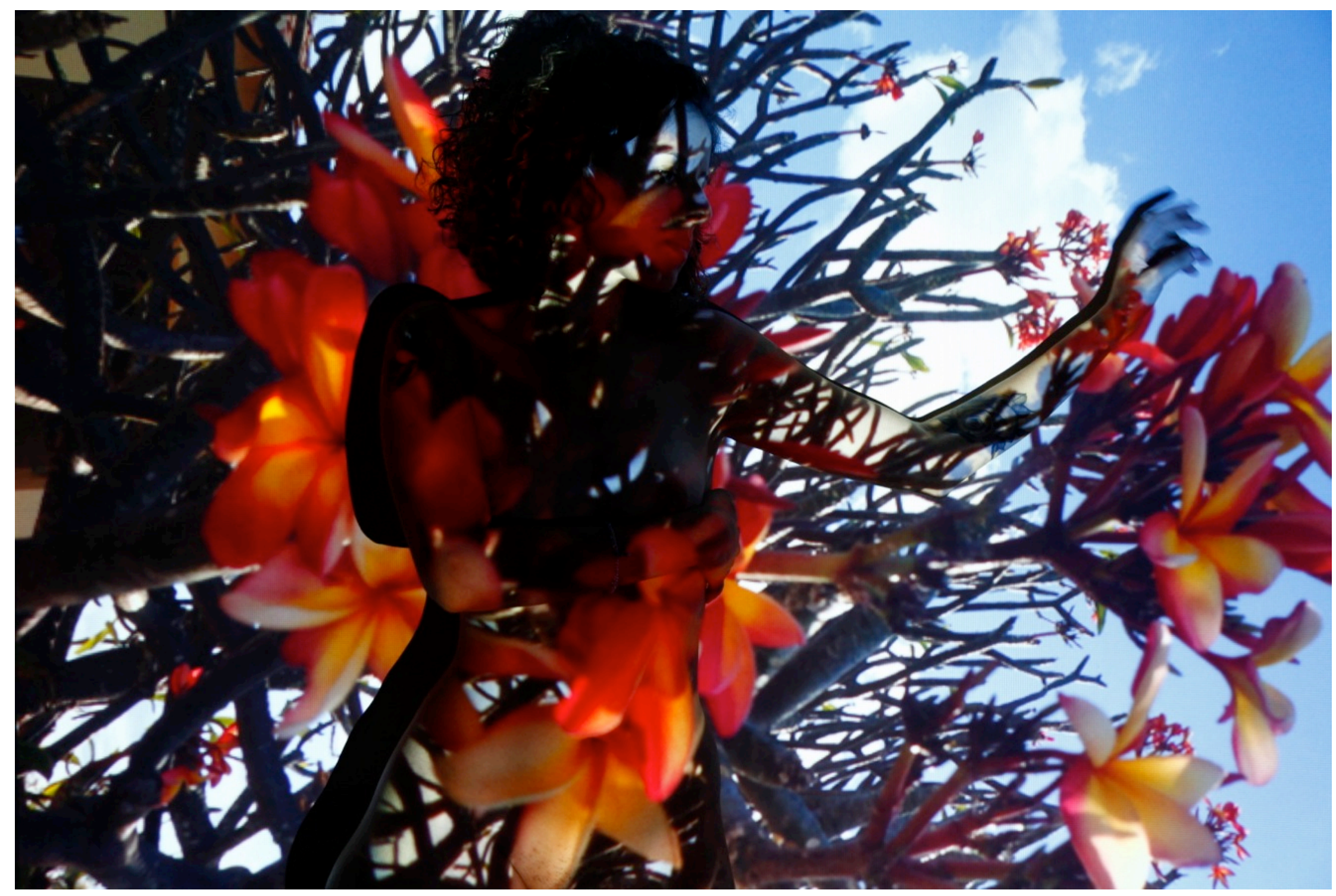

[Entre]linhas - Autorretrato, 2015. Projeção de fotografias pessoais sobre o corpo. Léia Magnólia. 


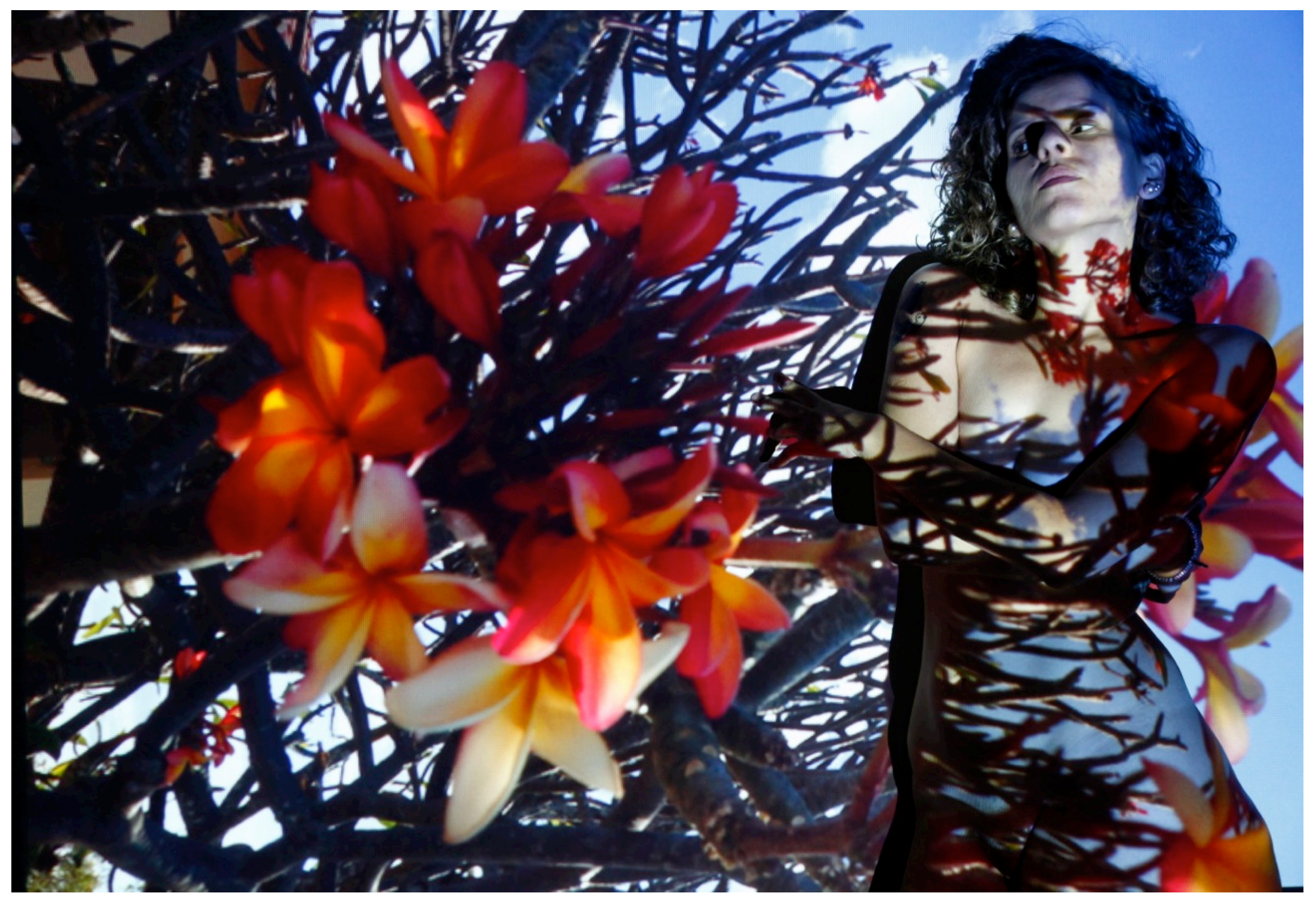

[Entre]linhas - Autorretrato, 2015. Projeção de fotografias pessoais sobre o corpo. Léia Magnólia. 


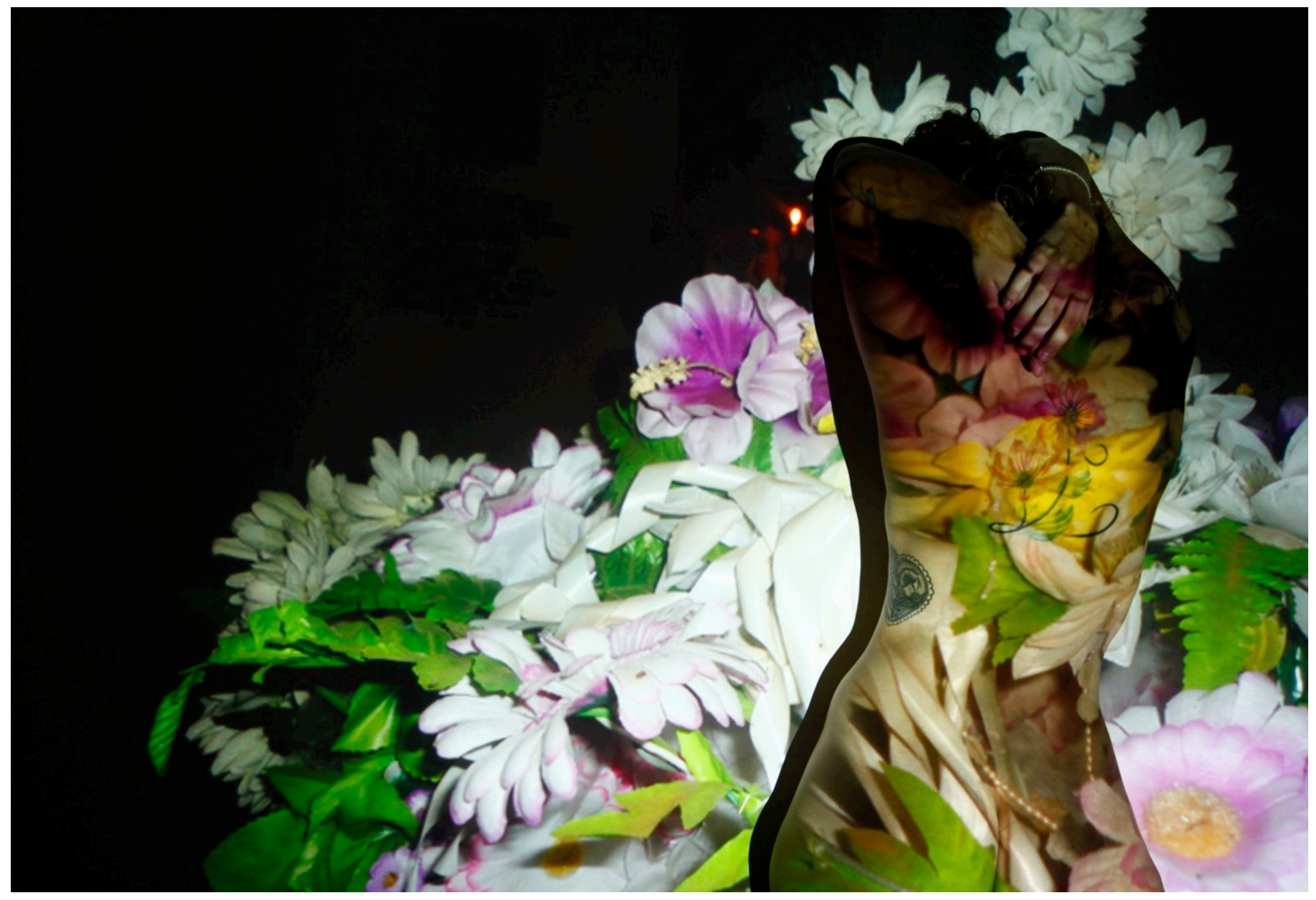

[Entre]linhas-Autorretrato, 2015. Projeção de fotografias pessoais sobre o corpo. Léia Magnólia. 


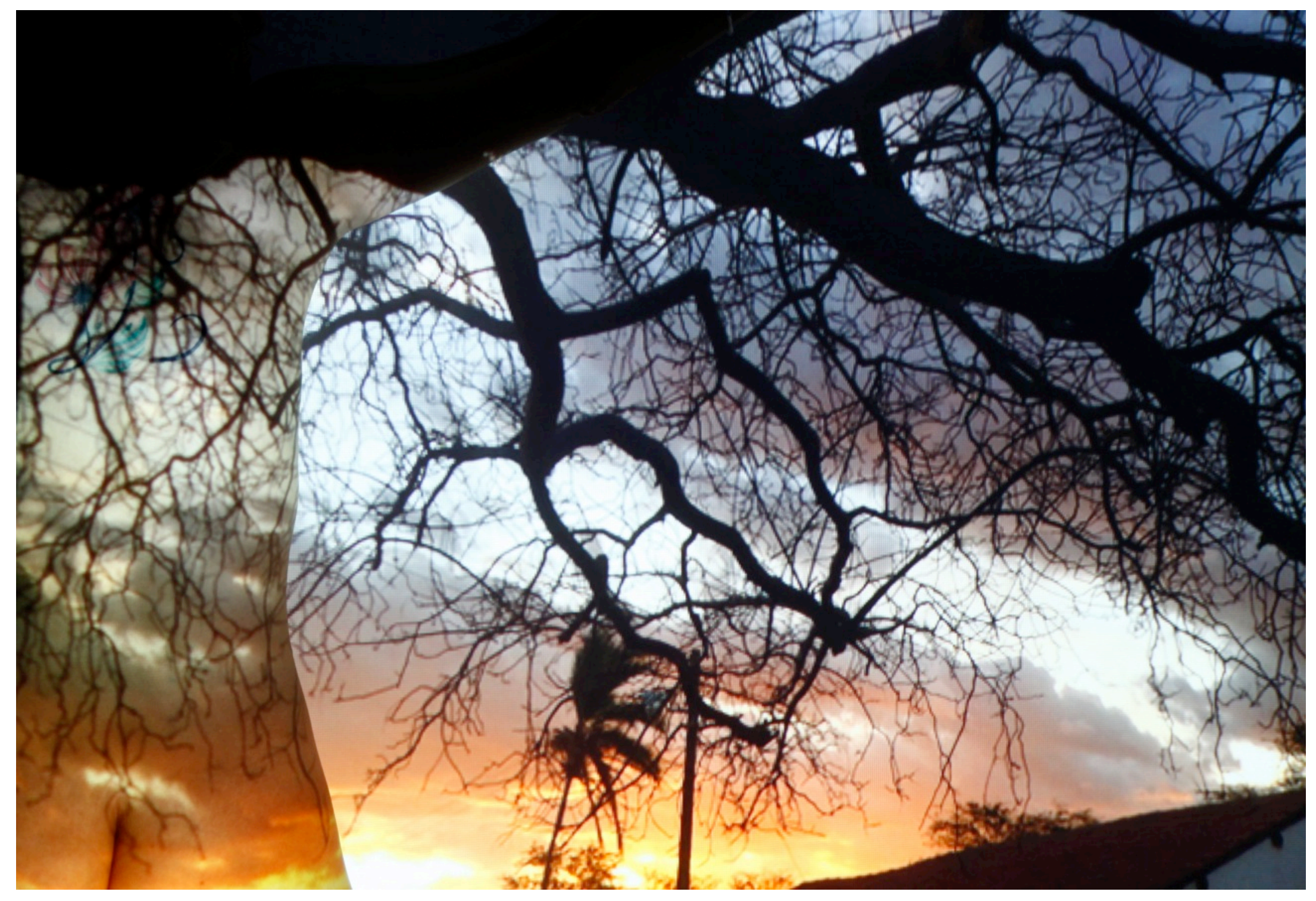

[Entre]linhas - Autorretrato , 2015. Projeção de fotografias pessoais sobre o corpo. Léia Magnólia. 


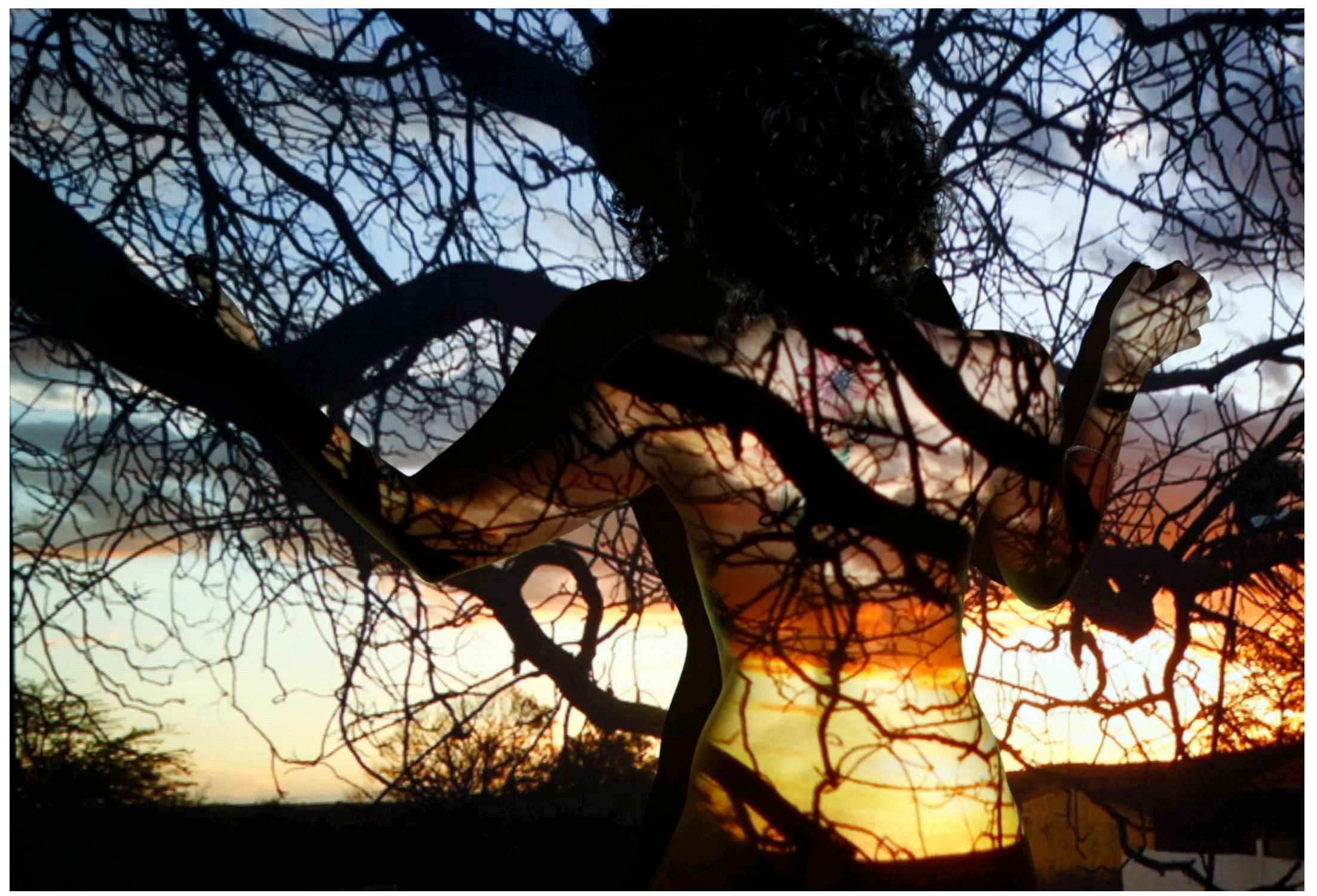

[Entre]linhas - Autorretrato , 2015. Projeção de fotografias pessoais sobre o corpo. Léia Magnólia. 
Nada melhor do que acordar com cólica, enjoada e menstruada no dia de hoje, 12 de maio de 2016. Com os hormônios à flor da pele, isso me faz lembrar que eu sou mulher e mesmo que eu consiga lidar com isso todos os meses, desde os 13 anos de idade. Mesmo que eu consiga conviver com o machismo nosso de cada dia, desde muito nova, porque isso sim, seria o "correto" para viver nessa sociedade hipócrita e escrota.

Mesmo que eu tenha aprendido tudo que seria o "ideal" para ser uma mulher exemplar... Eu percebo, hoje, como se fosse uma brincadeira ousada da natureza. Que acordar sangrando, literalmente, é como um post-it vermelho me lembrando que sou mulher, artista, educadora, sonhadora e que por um longo e incerto tempo serei, apenas isso. Triste, nunca imaginei me pegar chorando por causa de política. Aqui estou, aos prantos escrevendo isso enquanto penso: "O que vai ser do meu futuro?!".

E o máximo que consegui cogitar como uma singela forma de me manifestar foi : A partir de hoje vou dar um jeito de usar vermelho em tudo que eu fizer, por mais oculto que fique em minhas peças. Meu trabalho terá um vermelhinho, que é pra lembrar onde estou agora e até onde posso ir (isso me parece ser pouco). Desejo apenas boa sorte e força para todos nós.

Escrevi isso antes de sair de casa.

E não parou aí. Antes de ontem à noite (10/05) teve abertura da exposição de Anna Bella Geiger, "Gavetas de memórias". Tive a oportunidade de conversar com ela e compartilhar que eu e mais seis amigos artistas estamos com um coletivo de arte que se chama "Coletivo Gaveta", ainda estamos nos reunindo, projetando como nos lançar, tentando editais (enquanto existem) e sonhando. Falei também sobre o meu trabalho de Conclusão de Curso da Licenciatura em Artes Plásticas, intitulado "Gaveta Notória". Minha poética fala de memórias, o objeto (gaveta) foi uma instalação fotográfica. 
Anna Bella, delicadamente, acolheu a conversa, minha surpresa por não conhecer seu trabalho e tamanha coincidência do que estava acontecendo naquele momento. Disse para escrever pra ela. Me apresentou sua assistente que me passou o e-mail para entrar em contato. Conversamos sobre arte, política e vida. Logo depois aconteceu uma visita guiada por ela. Foram algumas horas de aprendizagem, esperança e compartilhamentos. Nos informaram que teria um espetáculo teatral, gratuito, nos três dias seguintes, que dialogava com a exposição. Essencialmente sobre memórias.

Imagina como foi isso pra mim...

Acordar no outro dia, menstruada com cólica e enxaqueca. Perceber que estamos vivendo um golpe com uma questão gritante de gênero. Sair de casa para aula de Cláudia Sanz, outra mulher maravilhosa, e ser bombardeada por sabedoria novamente. A noite ir pra um espetáculo que se chama "Solos de memória" que começava com uma performance na escada e depois seguia para o interior da galeria com a exposição de Anna Bella Geiger, presenciar um momento incrível com o ator olhando nos meus olhos, enquanto fazia o seu relato: "...Ouvi dizer que as pessoas que têm Alzheimer flutuam numa bruma".

Preciso nem dizer que cai no choro né?

O golpe me golpeou, vivo uma semana pra evidenciar que minhas escolhas não são acaso, algumas escritas são rabiscada pelo destino. Apanhei e muito emocionalmente, mas sei que me encontrei. 